\title{
Comparison of immune responses in calves fed heat-treated or unheated colostrum
}

\author{
S. L. Gelsinger and A. J. Heinrichs ${ }^{1}$ \\ Department of Animal Science, The Pennsylvania State University, University Park 16802
}

\begin{abstract}
Understanding the mechanisms that underlie neonatal immune function is important for appropriately treating and preventing disease. Cytokines provided in colostrum may affect immune development and function, but data describing cytokine absorption in calves and the effects of colostrum heat treatment on absorption are limited. The objectives of this experiment were to characterize immune responses in calves that received heat-treated $(\mathrm{HT})$ or unheated $(\mathrm{UH})$ colostrum (in terms of growth, rectal temperature, and blood cytokine and IgG concentrations) and to determine calves' ability to absorb IFN $\gamma$ and IL1 $\beta$ from HT and UH colostrum. A single large batch of colostrum was divided to create treatments. The HT colostrum was heated to $60^{\circ} \mathrm{C}$ for $60 \mathrm{~min}$. Both treatments were frozen until needed and warmed immediately before feeding. Bull calves $(\mathrm{n}=26)$ were randomly assigned to receive $8 \%$ of their birth weight in colostrum from 1 treatment at birth. Blood was collected at 0 and 24 to $48 \mathrm{~h}$ after birth for IL1 $\beta$, IFN $\gamma$, and IgG analyses. Subcutaneous injections of ovalbumin $(5.0 \mathrm{mg} / \mathrm{mL})$ were given at 14 and $35 \pm 3 \mathrm{~d}$ of age. Rectal temperature and growth were monitored for $10 \mathrm{~d}$ following each injection. Plasma samples were collected at 0,4 , 8 , and $12 \mathrm{~h}$ post-injection and daily for the subsequent $10 \mathrm{~d}$ to measure IL1 $\beta$, IFN $\gamma$, and IgG concentrations. Colostrum heat treatment failed to increase blood $\operatorname{IgG}$ concentrations or the apparent efficiency of IgG absorption. Serum IL1 $\beta$ concentrations were higher in UH calves 24 to $48 \mathrm{~h}$ after birth and remained higher than those in $\mathrm{HT}$ calves through $15 \mathrm{~d}$ of age. Both IFN $\gamma$ and $\mathrm{IgG}$ increased in response to ovalbumin injection; we observed no differences between treatments. Rectal temperature increased and peaked $12 \mathrm{~h}$ after injection at 14 and $35 \mathrm{~d}$. Growth rate was reduced by exposure to the foreign antigen. Interactions of calf age and colostrum treatment with time post-injection indicate
\end{abstract}

Received September 17, 2016.

Accepted January 9, 2017.

${ }^{1}$ Corresponding author: ajh@psu.edu that calves tended to show greater loss in average daily gain at $35 \mathrm{~d}$ than at $14 \mathrm{~d}$, and $\mathrm{UH}$ calves tended to recover greater rates of growth 6 to $10 \mathrm{~d}$ after receiving ovalbumin injection. Thus, feeding HT colostrum did not inhibit neonatal immune response, but it may have affected recovery from exogenous antigen challenge.

Key words: calf, immune response, cytokine, colostrum heat treatment

\section{INTRODUCTION}

Illnesses in calves and heifers can hinder them from achieving their genetic potential as mature cows (Heinrichs and Heinrichs, 2011). Lost production, combined with the costs associated with disease treatment, can limit dairy farm profitability. In addition, disease treatment and prevention using antibiotics faces increasing scrutiny in all species of livestock. A clear understanding of neonatal immune function and the external changes observed during an immune response may provide insights into possible means of disease intervention and times when intervention may be necessary.

One important factor that affects bovine neonatal immune function is the first feeding of colostrum (Nonnecke et al., 2012). Colostrum is a vital source of energy, minerals, and bioactive proteins and peptides for neonatal mammals (Kehoe et al., 2007). The majority of research investigating the role of colostrum on bovine neonatal immune function has focused on Ig absorption and "maternal interference," where absorbed Ig interact to prevent vaccine response (Windeyer et al., 2012; Yang et al., 2015). These data have great value, but with the development of new methods for assessing immune function, we need to evaluate aspects of colostrum and immune response in addition to Ig concentration. One factor that can provide some insight into innate and T-cell function is cytokine production. Hagiwara et al. (2000) described high concentrations of IL1 $\beta$, IFN $\gamma$, tumor necrosis factor $\alpha$ (TNF $\boldsymbol{\alpha})$, and IL6 in bovine colostrum, and decreases in each with subsequent milkings, similar to IgG (Elizondo-Salazar and Heinrichs, 2009). In mature animals, these cytokines are important for activating immune cells and 
stimulating proinflammatory responses (Kushibiki et al., 2003; Dinarello, 2009); they may also be involved in activating the neonatal immune response. Some cytokines, including IL1 $\beta$, IFN $\gamma$, and IL6, are absorbed by neonatal piglets and can affect piglet immune response, whereas others, including $\mathrm{TNF} \alpha$, do not appear to be absorbed, implying selective absorption (Nguyen et al., 2007). Calves appear to be able to absorb IL1 $\beta$ (Goto et al., 1997), but to our knowledge no studies have investigated calves' ability to absorb other cytokines or the possible effects of cytokines on immune response.

Surveys of colostrum bacterial concentration on dairy farms report values as high as $7.0 \log \mathrm{cfu} / \mathrm{mL}$ and $6.6 \log \mathrm{cfu} / \mathrm{mL}$ of total and coliform bacteria, respectively, due to post-harvest contamination (Houser et al., 2008). Heat treatment of colostrum is becoming common practice on dairy farms as a means of reducing bacterial infection in neonatal calves and increasing $\operatorname{IgG}$ absorption. Most recent data indicate that approximately $20 \%$ of dairy heifers in the United States receive heat-treated colostrum (NAHMS, 2016). Recommended heat-treatment protocols require that colostrum be heated to $60^{\circ} \mathrm{C}$ and maintained at that temperature for 30 to $60 \mathrm{~min}$, based on data that IgG concentration and colostrum viscosity are not largely affected by this temperature-time combination (Johnson et al., 2007; Elizondo-Salazar and Heinrichs, 2009). Colostrum heat treatment does reduce concentrations of IGF-1 and lactoferrin and may cause losses of other biologically active proteins, including cytokines ( $\mathrm{Gu}$ et al., 1991; Abd El-Fattah et al., 2014). Therefore, we hypothesized that calves would be able to absorb cytokines from colostrum, but that absorption would be lower in calves that received heat-treated colostrum. Further, we expected that reduced cytokine absorption would affect neonatal immune development. With the growing popularity of heat treatment, data are needed to determine any indirect effects on calf development. The objectives of this experiment were to determine calves' ability to absorb IFN $\gamma, \mathrm{TNF} \alpha$, and IL1 $\beta$ from heat-treated and unheated colostrum, and to characterize calves' growth and immune responses to an ovalbumin challenge.

\section{MATERIALS AND METHODS}

\section{Colostrum Treatments}

First-milking colostrum was collected from individual cows at the Pennsylvania State University dairy farm into clean $1.89 \mathrm{~L}$ containers and stored at $-20^{\circ} \mathrm{C}$ until treatment preparation. Approximately $114 \mathrm{~L}$ of colostrum was thawed at $4^{\circ} \mathrm{C}$, pooled, and divided into 2 equal batches. Half of the colostrum was poured into sterile $1.89 \mathrm{~L}$ containers and stored at $-20^{\circ} \mathrm{C}$ until needed for feeding to calves (unheated; UH). The other half was heated in stainless steel containers $(28$ $\mathrm{L}$ each) in a commercial steam vat pasteurizer (Girton Manufacturing Co., Millville, PA; Elizondo-Salazar and Heinrichs, 2009). All containers were fitted with agitators to ensure even heating of the colostrum. Colostrum temperature was monitored throughout heat treatment and never exceeded $60^{\circ} \mathrm{C}$. Colostrum was heated to $60^{\circ} \mathrm{C}$, maintained at that temperature for $60 \mathrm{~min}$, and then rapidly cooled, bottled in sterile $1.89 \mathrm{~L}$ containers, and stored at $-20^{\circ} \mathrm{C}$ until needed for feeding to calves (heat-treated; HT). Aliquots from both treatments were collected at the time of preparation and plated for total bacteria count. The remaining samples were stored at $-20^{\circ} \mathrm{C}$ for $\operatorname{IgG}$ analysis.

\section{Calves and Sampling}

All animal procedures were approved by the Pennsylvania State University Institutional Animal Care and Use Committee (IACUC \#46062). Twenty-six Holstein bull calves $(\mathrm{n}=13$ per treatment), sourced from a large local dairy farm, were enrolled in the experiment. Sample size was dictated by housing availability and determined to be sufficient based on the final sample size reported from a study that used a similar immune challenge (Ballou and DePeters, 2008). To be included in the experiment, calves must have had an unassisted birth observed by the lead author and a birth weight of 34 to $50 \mathrm{~kg}$. Calves were born onto a nylon tarp, immediately removed from the calving pen, and towel-dried to minimize bacterial exposure and prevent disease. Navels were coated with a $7 \%$ iodine tincture, and blood was collected from the jugular vein into serum separator tubes (Vacutainer, Becton Dickinson, Franklin Lakes, NJ) for analysis of IgG, IFN $\gamma$, IL1 $\beta$, and TNFo. Colostrum treatments were randomly assigned at birth using a random number generator, and each calf received a volume equal to $8 \%$ of its birth weight in a single feeding. Colostrum was thawed in a warm-water bath $\left(38\right.$ to $\left.43^{\circ} \mathrm{C}\right)$ and fed to calves using an esophageal feeder to ensure the treatment was completely consumed. Calves received colostrum within $4.5 \mathrm{~h}$ of birth and were transported to the Almquist Research Center at the Pennsylvania State University within $12 \mathrm{~h}$. All equipment for transporting and feeding calves was cleaned and sanitized between each calf or group of calves, as was the case of the truck for transport to the research center. A second blood sample was collected into a serum separator tube 24 to $48 \mathrm{~h}$ after birth. Blood samples were allowed to clot, then cen- 
trifuged at $1,500 \times g$ for $15 \mathrm{~min}$. Serum was collected in 2 separate tubes and stored at $-20^{\circ} \mathrm{C}$ for $\operatorname{IgG}$ and cytokine analysis.

At the research center, calves were housed in individual $2.1 \times 1.6 \mathrm{~m}$ pens, incapable of nose-to-nose contact, in a mechanically ventilated, heated barn with straw bedding provided as needed. A milk replacer that included 20\% CP and 20\% fat (NurseTrate Classic BT; ADM Alliance Nutrition Inc., Quincy, IL) was prepared to $12 \%$ solids, and calves were offered a volume equal to $6 \%$ of their birth weight twice per day at 0600 and $1800 \mathrm{~h}$, beginning at the first feeding time after $24 \mathrm{~h}$ of age. No antibiotics or anti-inflammatory drugs were used, except for lasalocid $(0.08 \mathrm{~g} / \mathrm{kg}$ of milk replacer $\mathrm{DM})$, which was included in the milk replacer as a coccidiostat, to avoid affecting immune response or development due to coccidiosis. The first calves ( $\mathrm{n}=$ 8) had scours within days, so an oral rehydration solution (Resorb; Zoetis Animal Health, Florham Park, NJ) was offered to all subsequent calves upon their arrival at the research center. Electrolyte solutions were also offered when calves were unable or unwilling to stand or consume their full volume of milk replacer; appeared dehydrated (sunken eyes, skin tenting test $>2$ s); exhibited a general, fecal, or respiratory health score $>2$; or had rectal temperature $>39.4^{\circ} \mathrm{C}$ per guidelines determined by a veterinarian before initiation of the study. Calves were drenched with any electrolyte solution that was not voluntarily consumed, and calves that received electrolyte solution for illness continued to receive 1 dose between milk replacer feedings until symptoms were alleviated. A texturized calf starter (20.7\% CP; ADM Milling, Overland Park, KS) was offered ad libitum beginning at $7 \mathrm{~d}$ of age, and calves were abruptly weaned at $46 \pm 3 \mathrm{~d}$. Free-choice water was offered throughout the experiment. Water bowls and milk buckets were cleaned and sanitized between each feeding. Milk replacer intake and health scores were monitored daily using a 5-point scoring system ( 1 = healthy; $5=$ severely ill) described by Lesmeister and Heinrichs (2004). Fresh starter was provided as needed. Starter refusals were collected weekly and weighed, and a sample of each refusal was dried at $55^{\circ} \mathrm{C}$ in a forced-air oven for $48 \mathrm{~h}$ to determine $\mathrm{DM}$ content (AOAC International, 2000). Subsamples of calf starter were sent to Cumberland Valley Analytical Services (Hagerstown, MD) for nutrient analysis (Table 1; AOAC International, 2000). Starch was determined using methods described by Hall (2009) and adjusted for free glucose.

To determine the effect of colostrum treatment on immune response, calves were given 2 subcutaneous injections containing $5.0 \mathrm{mg} / \mathrm{mL}$ of ovalbumin (\#A5503; Sigma-Aldrich Inc., St. Louis, MO). Ovalbumin was chosen to allow measurement of calf immune response without interference from maternal antibodies. Calves were divided into 3 groups based on age, such that each calf received the first injection at $14 \pm 3 \mathrm{~d}$ and the second injection at $35 \pm 3 \mathrm{~d}$ of age. Neonatal calves depend predominantly on their innate immune system and $\mathrm{T}$ cells for protection from disease during the first weeks of life (Chase et al., 2008). Neonatal B cells do not begin appreciable antibody production until 4 to 5 wk after birth (Chase et al., 2008). The first immune challenge was given subcutaneously at $14 \mathrm{~d}$ of age to compare the innate and developing T-cell responses between calves that had received UH and HT colostrum; the second subcutaneous injection allowed for comparison of B-cell responses as well. Plasma concentrations of ovalbuminspecific IgG, IFN $\gamma$, and IL1 $\beta$ were determined and used as indicators of B-cell, T-cell, and innate cell (mainly macrophage) activity, respectively. Challenge solutions ( $\mathrm{n}=6 ; 2$ challenge solutions for each of the 3 calf groups) were prepared $12 \mathrm{~h}$ before injection by dissolving ovalbumin $(5.0 \mathrm{mg} / \mathrm{mL})$ and Quil A adjuvant $(0.5$ $\mathrm{mg} / \mathrm{mL}$; Accurate Chemical and Scientific Corp., Westbury, NY) in sterile PBS. Aliquots of each solution were plated for total bacteria count to confirm sterility. After the first challenge was given, bacteria were discovered from the plated sample. By process of elimination using blood agar plates, the ovalbumin protein powder was determined to be the source of the contamination. Samples of the bacteria were submitted to the Pennsylvania State University Diagnostic Laboratory, and the bacteria were identified as nonpathogenic Enterococcus spp. Because the bacteria were nonpathogenic, we used the same ovalbumin powder for subsequent challenge solutions, and plated each solution to monitor bacteria concentration. Bacteria counts were 200 and $40 \mathrm{cfu} / \mathrm{mL}$ following $48 \mathrm{~h}$ of incubation at $37^{\circ} \mathrm{C}$ for the first challenges given to calves in groups 2 and 3 , respectively

Table 1. Chemical composition (\% of DM unless otherwise noted) of calf starter mix offered to calves starting at $3 \mathrm{~d}$ of age

\begin{tabular}{lc}
\hline Item & Value \\
\hline $\mathrm{DM}(\%)$ & 87.6 \\
$\mathrm{CP}$ & 20.7 \\
Crude fiber & 5.6 \\
Crude fat & 4.6 \\
Ash & 7.0 \\
Starch & 35.1 \\
$\mathrm{Ca}$ & 1.08 \\
$\mathrm{P}$ & 0.65 \\
$\mathrm{Mg}$ & 0.31 \\
$\mathrm{~K}$ & 1.37 \\
$\mathrm{Na}$ & 0.42 \\
$\mathrm{Fe}(\mathrm{mg} / \mathrm{kg})$ & 237 \\
$\mathrm{Mn}(\mathrm{mg} / \mathrm{kg})$ & 138 \\
$\mathrm{Zn}(\mathrm{mg} / \mathrm{kg})$ & 151 \\
$\mathrm{Cu}(\mathrm{mg} / \mathrm{kg})$ & 50 \\
\hline
\end{tabular}


and 60,80 , and $180 \mathrm{cfu} / \mathrm{mL}$ for the second challenges given to age groups 1,2 , and 3 , respectively. Plates from the initial challenge given to calves in group 1 were incubated longer than $48 \mathrm{~h}$, because no bacterial growth was expected, and therefore colonies could not be enumerated.

Rectal temperature was measured $24 \mathrm{~h}$ and $1 \mathrm{~h}$ before each injection, and when both pre-injection rectal temperature measurements were $>39.4^{\circ} \mathrm{C}$, injection was delayed and an electrolyte solution was offered until rectal temperature dropped into the normal range. Injection was delayed for 1 calf due to elevated temperature. The cause of the elevated temperature was not defined, and no other clinical signs of disease were observed. All calves received the injection within the target ages of 14 and $35 \pm 3 \mathrm{~d}$. Immune-challenge injections were given before the morning feeding. At the time of injection, no calves were receiving oral electrolytes for any reason. Blood samples were collected into evacuated tubes containing sodium heparin (Vacutainer; Becton Dickinson) via jugular venipuncture immediately before injection; 4, 8, and $12 \mathrm{~h}$ post-injection; and before the morning feeding for the subsequent $10 \mathrm{~d}$. Hematocrit was measured and whole blood samples were centrifuged at $1,500 \times g$ for $15 \mathrm{~min}$. Plasma was collected into separate vials and stored at $-20^{\circ} \mathrm{C}$ for $\operatorname{IgG}$ and cytokine analysis. Rectal temperature was measured at the time of each blood sampling, and oral electrolytes were offered as supportive therapy when rectal temperature was $>39.4^{\circ} \mathrm{C}$. Calves' $\mathrm{BW}$ was measured before the morning feeding on $\mathrm{d}-1$ and 0,5 and 6 , and 10 and 11, relative to injection. Weights were averaged across consecutive days by calf to determine the effect of the immune challenge on ADG.

\section{Total IgG and Ovalbumin-Specific IgG}

Concentration of $\mathrm{IgG}$ was determined in colostrum and serum samples collected at birth and 24 to 48 $\mathrm{h}$ after birth using radial immunodiffusion (RID; \#728411; Triple J Farms, Bellingham, WA) and ELISA (Bethyl Laboratories, Montgomery, TX). Many studies have reported values from either RID or ELISA analyses, but data from our laboratory indicates that RID and ELISA assays yield different values for the same samples (Gelsinger et al., 2015b). More data are needed from both assays to allow for the comparison of values between them; therefore, values from both are reported here. Both procedures were used according to the manufacturer's directions, and samples were tested using standards provided with each kit. Colostrum samples were diluted $1: 10$ in a $0.85 \%$ saline solution before RID analysis, and serum samples were tested neat. Dilution factors for ELISA were 1:500,000 and 1:100,000 in Tris buffer saline solution with Tween 20 (TBST) for colostrum and serum, respectively. The complete procedure was run twice for RID and 3 times for ELISA analyses. Coefficients of variation for RID and ELISA assays were 2.5 and $3.6 \%$, respectively, for colostrum and 0.8 and $4.2 \%$ for serum.

Briefly, RID analysis was conducted by dispensing 5 $\mu \mathrm{L}$ of the diluted sample into each well of the agarose gel provided. Gels were sealed in an opaque envelope, and precipitin ring diameters were measured after a $24 \mathrm{~h}$ incubation at $20^{\circ} \mathrm{C}$ using a peak scale loupe $7 \times(\# 1975$; GWJ Company, Peak Optics, Hacienda Heights, CA).

For the ELISA analysis, wells were coated with affinity-purified IgG (\#A10-118A; Bethyl Laboratories,) diluted in coating buffer $\left(2.65 \mathrm{~g} / \mathrm{L} \mathrm{Na} \mathrm{NO}_{3}, 2.1 \mathrm{~g} / \mathrm{L}\right.$ $\mathrm{NaHCO}_{3}$ ). Diluted samples were added after residual coating antibody was removed, and plates were washed with TBST. Horseradish peroxidase conjugated antibody produced in sheep against bovine IgG heavy chain (\#A10-118P; Bethyl Laboratories) was added to each well, and following a $1 \mathrm{~h}$ incubation and subsequent wash procedure, 3,3',5,5'-tetramethylbenzidine ELISA peroxidase substrate (Rockland Immunochemicals Inc., Gilbertsville, PA) was added to each well and allowed to react for 15 to $20 \mathrm{~min}$. The enzyme reaction was ended by adding $0.2 \mathrm{M}$ sulfuric acid, and absorbance was read at a wavelength of $450 \mathrm{~nm}$ (Victor ${ }^{3}$ Multilabel Counter model 1420; PerkinElmer Life Sciences, Waltham, MA). Our laboratory found greater consistency in results from this protocol provided by the antibody manufacturer (Bethyl Laboratories) than with the previously reported modification (Gelsinger et al., 2015b).

Total IgG concentration was analyzed in plasma collected during immune challenges by ELISA alone to maintain method consistency between total and ovalbumin-specific IgG and used the same protocol and dilution factors described for serum. Detection of ovalbumin-specific IgG followed the same protocol as that of total IgG, except that samples were not diluted before analysis and wells were coated with ovalbumin protein (\#A5503; Sigma-Aldrich, Inc.) diluted in the same coating buffer $(1.6 \mathrm{mg} / \mathrm{L}$ ovalbumin) rather than a coating antibody. Mean coefficients of variation for total IgG and ovalbumin-specific IgG assays for plasma were 4.4 and $3.6 \%$, respectively.

\section{Cytokine Analysis}

Cytokine analysis was conducted using a prototype bovine cytokine multiplex assay developed for serum and plasma (\#MSD-101112 LA prototype protocol; 
Meso Scale Delivery, Rockville, MD). Other studies have shown rapid increases of cytokines in response to immune challenge, with peak concentration at 2 to $4 \mathrm{~h}$ post-challenge (Oliver et al., 1993; Benjamin et al., 2016). The earliest sample collected in the current study was taken $4 \mathrm{~h}$ post-injection. Therefore, to capture the most complete profile of cytokine changes and limit the total cost of analysis, only duplicate plasma samples collected at $0,4,8,12,24$, and $48 \mathrm{~h}$ relative to each challenge were thawed and analyzed for cytokine concentration. Prototype 96-well plates were provided with target antibodies for bovine IFN $\gamma$, IL1 $\beta$, and TNF $\alpha$ pre-coated on 3 spatially separated areas in each well (\#N45ZA-1; Meso Scale Delivery). Plates, samples, and all solutions were brought to $20^{\circ} \mathrm{C}$ before initiating the analysis and maintained at this temperature for the duration of the protocol. Plates were blocked for $30 \mathrm{~min}$ with $25 \mu \mathrm{L}$ of MSD diluent 7 (\#R54BB-3; Meso Scale Delivery). Standard solutions were created by serially diluting custom stock solutions (\#C01XX-2; Meso Scale Delivery) in the same diluent. Detection ranges for IFN $\gamma$, IL1 $\beta$, and TNF $\alpha$ were 1.2 to $5,000 \mathrm{pg} / \mathrm{mL}, 9.8$ to $40,000 \mathrm{pg} / \mathrm{mL}$, and 2.4 to 10,000 $\mathrm{pg} / \mathrm{mL}$, respectively. Samples were tested without dilution. All standard solutions and samples were tested in duplicate wells. Following a $2 \mathrm{~h}$ incubation, standard solutions and samples were removed, wells were washed with PBS containing $0.05 \%$ Tween 20 (PBST), and customized detection antibodies (\#D20XX-1; Meso Scale Delivery) diluted in MSD diluent 8 (\#R54BA-3; Meso Scale Delivery) were added to each well. Following a second $2 \mathrm{~h}$ incubation, detection antibodies were removed, plates were washed a final time with PBST, $150 \mu \mathrm{L}$ of MSD read buffer (\#R92TC-2; Meso Scale Delivery) were added to each well, and the luminescent signal was measured using an MSD Sector Imager 2400 (Meso Scale Delivery). Values were accepted when duplicate CV $<21 \%$. Samples with a concentration below the detectable range for a cytokine were removed from the analysis for that cytokine. Mean coefficients of variation for IFN $\gamma, \mathrm{IL} 1 \beta$, and $\mathrm{TNF} \alpha$ were 2.9, 14.2, and $28.4 \%$, respectively. Results from $\mathrm{TNF} \alpha$ analysis are not reported, because only 113 samples contained detectable concentrations of $\mathrm{TNF} \alpha$ and also attained a $\mathrm{CV}<21 \%$, making comparisons impossible for any time point.

A subset of serum samples ( $\mathrm{n}=38 ; 2$ per calf) collected at birth and 24 to $48 \mathrm{~h}$ after birth were randomly selected for cytokine analysis to determine changes in concentrations of IL1 $\beta$ and IFN $\gamma$ before and after colostrum consumption, and to optimize cost efficiency. Methods and acceptance criteria were identical to those described for plasma, above.

\section{Statistical Analysis}

All analyses were conducted using PROC MIXED in SAS (version 9.4; SAS Institute, Cary, NC). Conditional residual plots were used to assess the normality of the data. When non-normal distributions of residuals were observed, data were transformed for analysis. Backtransformed values are reported for ease of interpretation. Plasma IgG concentration 24 to $48 \mathrm{~h}$ after birth was compared between treatments, and birth weight was included as a covariate, because the volume of colostrum offered to calves was based on birth weight. The apparent efficiency of absorption (AEA) was calculated according to the equation reported by Quigley and Drewry (1998). Birth weight was not included as a covariate for AEA comparison between treatments, because it was included in the AEA calculation (Quigley and Drewry, 1998). Colostrum treatment, time point ( 0 vs. 24 to $48 \mathrm{~h}$ ), and their interaction were included in the model to determine changes in plasma concentrations of IFN $\gamma$ and IL1 $\beta$. Time point was included as a repeated measure, with calf as the subject. Calf was not included as a random effect in models for passive transfer of IgG and cytokines to avoid model overspecification.

The mean number of doses of electrolytes per calf was compared between treatments using PROC MIXED, with colostrum treatment as the only fixed effect. The frequency of electrolyte feeding was plotted across treatments, and Levene's test for homogeneity was used to confirm normality $(P=0.15)$ before analysis.

Colostrum treatment, week of age, and their interaction were used to model starter DMI. Degrees of freedom were calculated using the Kenward-Roger method. Week was included as a repeated effect, using calf $\times$ treatment interaction as the subject, and an autoregressive covariance structure was specified.

All data from each immune challenge were analyzed using the following model:

$$
\begin{gathered}
Y_{i j k l}=\mu+\alpha_{i}+\beta_{j}+\gamma_{k}+c(\beta) 1+\alpha \beta_{i j}+\alpha \gamma_{i k} \\
+\beta \gamma_{j k}+\alpha \beta \gamma_{i j k}+\varepsilon,
\end{gathered}
$$

where $Y_{i j k l}$ represents the response variable; $\alpha_{i}$ represents calf age $(1,2 ; 14$ or $35 \mathrm{~d}) ; \beta_{j}$ represents colostrum treatment $(1,2$; HT or $\mathrm{UH}) ; \gamma_{k}$ represents the time point $(1,2,1 \ldots 3,1 \ldots 5$, or $1 \ldots 13$; ADG, $\mathrm{BW}$, cytokine, rectal temperature, and IgG analysis, respectively); $c(\beta) 1$ represents the random effect of calf nested within treatment $(1 \ldots 26)$; and $\varepsilon$ represents residual error. Time point was included as a repeated effect for each combination of calf $\times$ treatment $\times$ challenge. An autoregressive covariance matrix was speci- 
fied for cytokine, rectal temperature, and $\operatorname{IgG}$ analyses. The BW and ADG analyses incorporated an unstructured covariance matrix due to a limited number of observations. Degrees of freedom were calculated using the Kenward-Roger method. The slice option was used to perform preplanned contrasts between treatments at each time point within each challenge.

\section{RESULTS}

Colostrum treatments and calves assigned to each are described in Table 2, and values from RID and ELISA for colostrum IgG are given. The ELISA has been shown to underestimate IgG concentration relative to RID, and direct comparison of values between methods is discouraged (Gelsinger et al., 2015b). The majority of this discussion will focus on the results from RID, because it is the most commonly used method in published research and the basis of industry recommendations for colostrum quality and passive transfer of IgG (Pritchett et al., 1994; Tyler et al., 1996; Bielmann et al., 2010). More recently, researchers have reported values from ELISA, so we have provided ELISA values for comparison with future research.

The mass of colostrum consumed was based on calves' birth weight, and was not different between treatment groups. However, HT calves consumed $38.2 \mathrm{~g}$ less IgG due to losses in IgG concentration during heat treatment. Still, despite the differences in ingested mass of IgG, neither serum IgG nor AEA were affected by treatment. Calves that received HT colostrum tended to receive colostrum at an earlier age than $\mathrm{UH}$ calves $(P=0.08)$, but all calves received colostrum within 4.5 $\mathrm{h}$ of birth (range 2.0 to $4.3 \mathrm{~h}$ ), within the time period for maximum IgG absorption (Stott et al., 1979).

Mean serum IL1 $\beta$ and IFN $\gamma$ concentrations at birth and 24 to $48 \mathrm{~h}$ after birth are given in Table 3. Reported means are based on samples that contained detectable concentrations and duplicates with CV $<21 \%$. All samples contained detectable IFN $\gamma$ concentrations, and we removed only 2 values due to unacceptable $\mathrm{CV}$. None of the samples collected at birth contained detectable amounts of IL1 $\beta$, so we could not test the effect of time after birth on IL1 $\beta$ concentration. The final statistical model for IL1 $\beta$ included only the effect of colostrum treatment. Each of the 24 to $48 \mathrm{~h}$ serum samples $(\mathrm{n}=19)$ contained detectable amounts of IL1 $\beta$, but we removed 2 values for CV $\geq 21 \%$. Samples removed from analysis for IFN $\gamma$ were different from those removed from IL1 $\beta$ analysis. The final number of samples included in each mean is also given in Table 3. Heat treatment of colostrum did not affect calf serum IFN $\gamma$ concentration $(P=0.39)$ but did reduce serum IL1 $\beta$ at 24 to $48 \mathrm{~h}(P<0.01)$.

The body temperatures of calves during immune challenges at 14 or $35 \mathrm{~d}$ of age are shown in Figure 1; BW and ADG values are reported in Table 4. Calf body temperature increased immediately after injection, peaked $12 \mathrm{~h}$ post-injection, and returned to baseline by $72 \mathrm{~h}$. Body temperature response was similar between treatments $(P=0.29)$ and did not change with calf age $(P=0.09)$. Calves' BW and ADG were greater at $35 \mathrm{~d}$ than at $14 \mathrm{~d}$, as would be expected in growing calves. Numerical differences in birth weight between treatments were maintained throughout the experiment, with $\mathrm{UH}$ calves averaging 1.1 to $1.9 \mathrm{~kg}$ heavier than

Table 2. Summary of colostrum treatments and feeding, calf birth weight, and IgG absorption as measured by radial immunodiffusion (RID) or ELISA

\begin{tabular}{|c|c|c|c|c|}
\hline Item & Unheated & Heat-treated $^{1}$ & SEM & $P$-value \\
\hline \multicolumn{5}{|l|}{ Colostrum IgG $(\mathrm{mg} / \mathrm{mL})$} \\
\hline RID & 117.3 & 106.3 & - & - \\
\hline ELISA & 71.6 & 66.2 & - & - \\
\hline \multicolumn{5}{|l|}{ Colostrum bacteria (log cfu/mL) } \\
\hline Standard plate count & 4.1 & 1.3 & - & - \\
\hline Coliforms & 2.8 & 0.0 & - & - \\
\hline \multicolumn{5}{|l|}{ Mass of IgG consumed ( $\mathrm{g}$ ) } \\
\hline RID & 359.6 & 321.4 & 9.8 & 0.01 \\
\hline ELISA & 219.4 & 200.2 & 6.0 & 0.03 \\
\hline Age at colostrum feeding $(\mathrm{h})$ & 3.1 & 2.7 & 0.2 & 0.08 \\
\hline Birth weight $(\mathrm{kg})$ & 41.8 & 40.9 & 1.2 & 0.58 \\
\hline \multicolumn{5}{|l|}{ Serum IgG $(\mathrm{mg} / \mathrm{mL})$} \\
\hline RID & 23.3 & 20.5 & 1.9 & 0.38 \\
\hline ELISA & 21.7 & 20.4 & 1.8 & 0.66 \\
\hline \multicolumn{5}{|l|}{$\operatorname{AEA}^{2}(\%)$} \\
\hline RID & 25.7 & 22.9 & 1.2 & 0.82 \\
\hline ELISA & 38.3 & 34.9 & 2.5 & 0.86 \\
\hline
\end{tabular}

${ }^{1}$ Colostrum heated to $60^{\circ} \mathrm{C}$ for $60 \mathrm{~min}$.

${ }^{2}$ Apparent efficiency of absorption of IgG. 

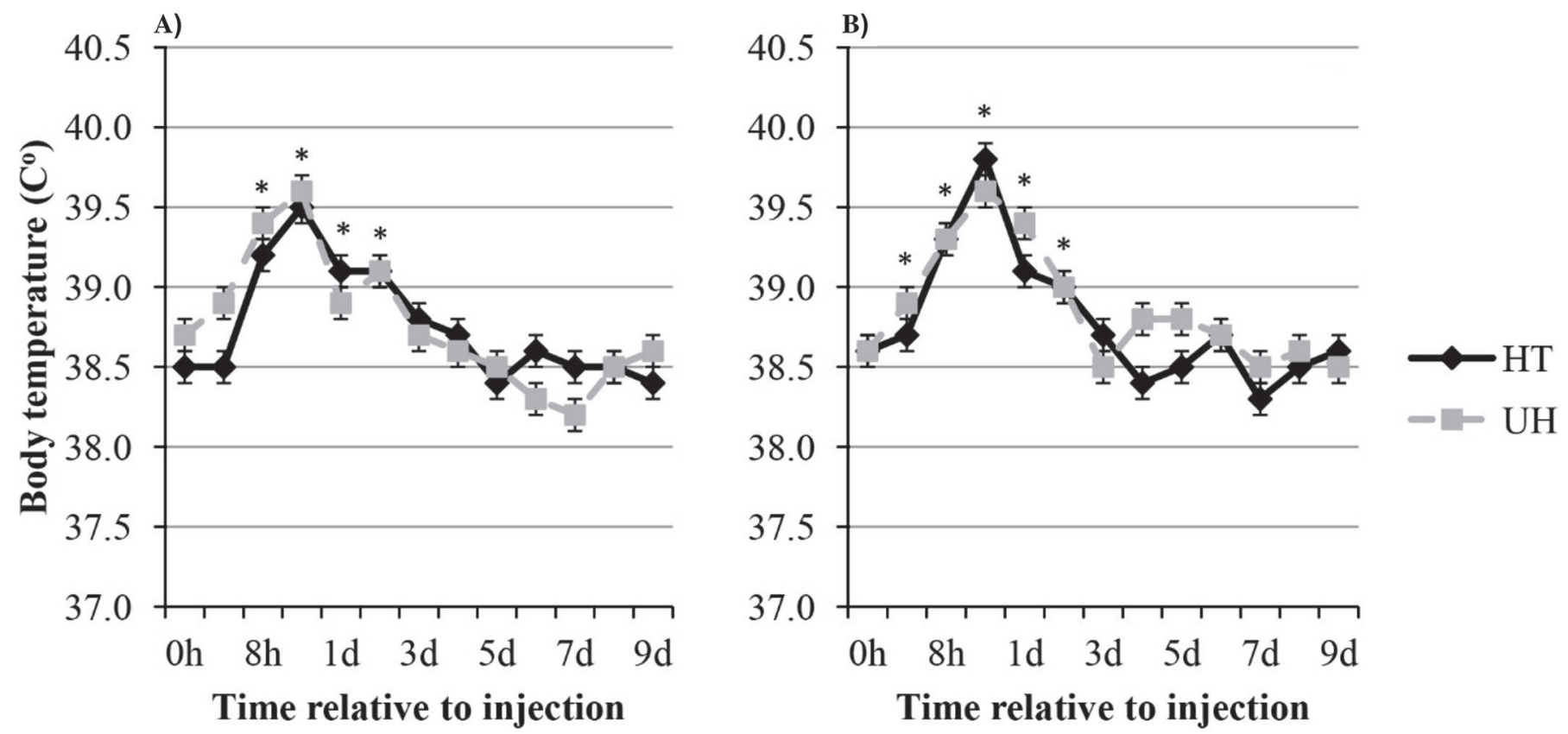

Figure 1. Rectal temperature after subcutaneous injection with $5.0 \mathrm{mg} / \mathrm{mL}$ ovalbumin at (A) $14 \mathrm{~d}$ and (B) $35 \mathrm{~d}$ of age in calves that received heat-treated $\left(60^{\circ} \mathrm{C}, 60 \mathrm{~min} ; \mathrm{HT}\right)$ or unheated $(\mathrm{UH})$ colostrum at birth. Rectal temperature was not affected by colostrum treatment $(P>0.05)$ or calf age $(P>0.05)$, but changed with time after injection $(P<0.01)$. ${ }^{*}$ Indicates rectal temperature was different from that at time 0 . Error bars represent standard errors of individual treatment means at each time point.

HT calves, but these differences were not significant. Growth rate was lower from 0 to $5 \mathrm{~d}$ post-injection than from 6 to $10 \mathrm{~d}$ post-injection for both treatments. However, we expected this, because nutrients that would be used for growth are shuttled to immune cells to produce signaling molecules, induce fever, and support cellular expansion and other functions (Lochmiller and Deerenberg, 2000).

We observed no difference in the frequency of electrolyte feeding between treatments $(P>0.05$; data not shown). The number of feedings ranged from 1 to 11 per calf; means for UH and HT calves were 3.9 and 5.2, respectively. Elevated body temperature $\left(>39.4^{\circ} \mathrm{C}\right)$ was the most common reason for electrolyte feeding, because all calves experienced a transient increase in body temperature during the first days following ovalbumin injection. Other reasons for feeding electrolytes were fecal, respiratory, or general scores $>2(\mathrm{n}=14$ calves $)$, and refusal to consume milk replacer ( $\mathrm{n}=10$ calves). No calves were removed from the trial due to illness. This study was not powered to assess general health outcomes, but larger studies with adequate power have indicated that calves fed heat-treated colostrum are at lower risk of treatment for scours (Godden et al., 2012).

Changes in plasma IFN $\gamma$ concentration following immune challenge injection are shown in Figure 2. Plasma

Table 3. Serum cytokine concentration at birth and 24 to $48 \mathrm{~h}$ of age in calves fed heat-treated or unheated colostrum

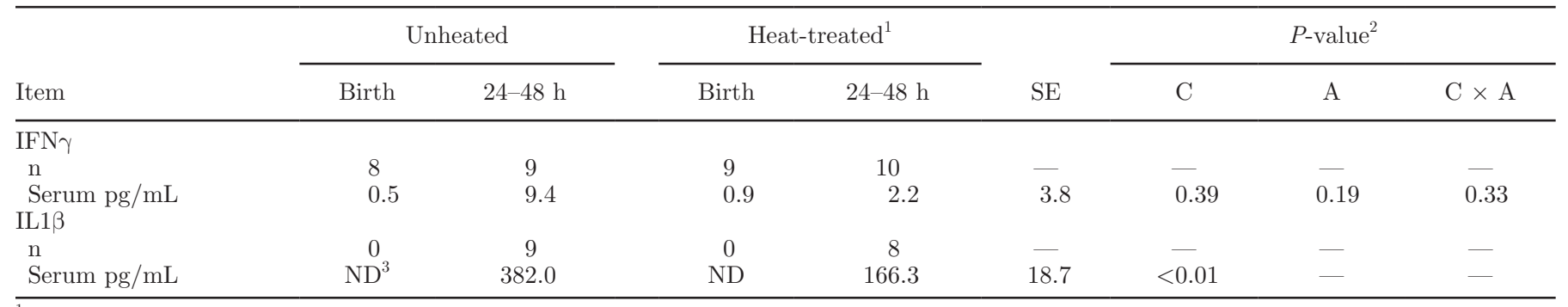

${ }^{1}$ Colostrum heated to $60^{\circ} \mathrm{C}$ for $60 \mathrm{~min}$.

${ }^{2} \mathrm{C}=$ colostrum treatment, $\mathrm{A}=$ calf age $(14$ or $35 \mathrm{~d})$.

${ }^{3}$ Not detected. 
IFN $\gamma$ increased gradually from 8 to $12 \mathrm{~h}$ post-injection, began to decrease by $48 \mathrm{~h}$, and was similar at 14 and 35 $\mathrm{d}$ of age. We observed no differences due to treatment.

Colostrum treatment did not affect overall IL1 $\beta$ concentration; however, applying slice analysis to the interaction of calf age and colostrum treatment $(P=$ $0.15)$ revealed lower plasma IL1 $\beta$ in HT calves at 14 $\mathrm{d}(P=0.03)$, but no differences between treatments at $35 \mathrm{~d}(P=0.96)$. This may have been related to differences in IL1 $\beta$ observed in serum $48 \mathrm{~h}$ after birth. Both IL1 $\beta$ and IFN $\gamma$ concentrations were lower following the second ovalbumin injection, and IL1 $\beta$ did not change in response to the ovalbumin injection at $35 \mathrm{~d}$. This may have been due to increased B-cell activity indicated by antibody production shown in Figure 3 . Neonatal calves may also develop some T-cell memory, which could explain the reduction in IFN $\gamma$ during the second challenge period (Nonnecke et al., 2005).

Total $\mathrm{IgG}$ concentration was 17.8 and $18.3 \pm 0.88$ $\mathrm{mg} / \mathrm{mL}$ in UH and HT calves, respectively, before the ovalbumin injection at $14 \mathrm{~d}$ and decreased steadily during the challenge period (data not shown). Plasma IgG concentration stabilized near $10 \mathrm{mg} / \mathrm{mL}$ by $35 \mathrm{~d}$ and did not change for the duration of the experiment. These data agree with reports from others that indicated circulating IgG peaks in calves at $48 \mathrm{~h}$ of age and decreases during the initial weeks of life (ElizondoSalazar and Heinrichs, 2009).

\section{DISCUSSION}

This was the first study we know of to attempt to directly characterize cytokine absorption and immune response in calves fed heat-treated colostrum. This study was limited by sample number and few specific analyses, but we believe these results provide valuable information about calf immune development and the application of colostrum heat treatment when colostrum quality is very high.

\section{IgG Absorption}

Compared with unheated colostrum, heating colostrum to $60^{\circ} \mathrm{C}$ for 30 to 60 min reduces bacterial counts (Godden et al., 2006; Elizondo-Salazar et al., 2010), minimally affects $\operatorname{IgG}$ concentration and viscosity (McMartin et al., 2006; Elizondo-Salazar et al., 2010), and improves the absorption of IgG by calves (Johnson et al., 2007; Elizondo-Salazar and Heinrichs, 2009). Heat treatment failed to increase IgG absorption in the present study.

Other studies that reported greater AEA and blood IgG concentrations in calves fed heat-treated colostrum used colostrum of lower initial IgG and higher initial bacterial concentrations (Johnson et al., 2007; Elizondo-Salazar and Heinrichs, 2009; Kryzer et al., 2015). Johnson et al. (2007) reported $23 \%$ higher serum IgG concentrations when the total bacterial count was reduced from 4.7 to $2.9 \log \mathrm{cfu} / \mathrm{mL}$. Elizondo-Salazar and Heinrichs (2009) heated $76.4 \mathrm{mg} \mathrm{IgG} / \mathrm{mL}$ colostrum to $60^{\circ} \mathrm{C}$ for $30 \mathrm{~min}$, reduced total bacteria from 5.5 to 3.1 $\log \mathrm{cfu} / \mathrm{mL}$, and reported $18 \%$ higher IgG concentration in calves fed heat-treated colostrum. A more recent study using 112 Jersey calves and a 60 min heat treatment also found higher serum IgG concentration (16\%) with heat-treated colostrum than with refrigerated or frozen fresh colostrum (Kryzer et al., 2015). Initial bacterial and IgG concentrations in the latter study were $5.3 \mathrm{log} \mathrm{cfu} / \mathrm{mL}$ and $79.2 \mathrm{mg} / \mathrm{mL}$, respectively (Kryzer et al., 2015). The initial total bacterial count in the present study was $4.1 \log \mathrm{cfu} / \mathrm{mL}$ total bacteria, below the $4.3 \log \mathrm{cfu} / \mathrm{mL}$ recommended for milk to be fed to calves and lower than initial counts in colostrum used by others (Johnson et al., 2007; Godden, 2008; Elizondo-Salazar and Heinrichs, 2009). Heat treatment reduced total bacterial count to $1.3 \log \mathrm{cfu} / \mathrm{mL}$ and eliminated coliform bacteria from an initial count of $2.8 \log \mathrm{cfu} / \mathrm{mL}$. Colostrum IgG was reduced by $9.4 \%$ $(11.0 \mathrm{mg} / \mathrm{mL})$, resulting in $38.2 \mathrm{~g}$ less IgG ingestion by

Table 4. Growth and health measurements after subcutaneous injection with $5.0 \mathrm{mg} / \mathrm{mL}$ ovalbumin at 14 and $35 \mathrm{~d}$ of age in calves fed heattreated or unheated colostrum

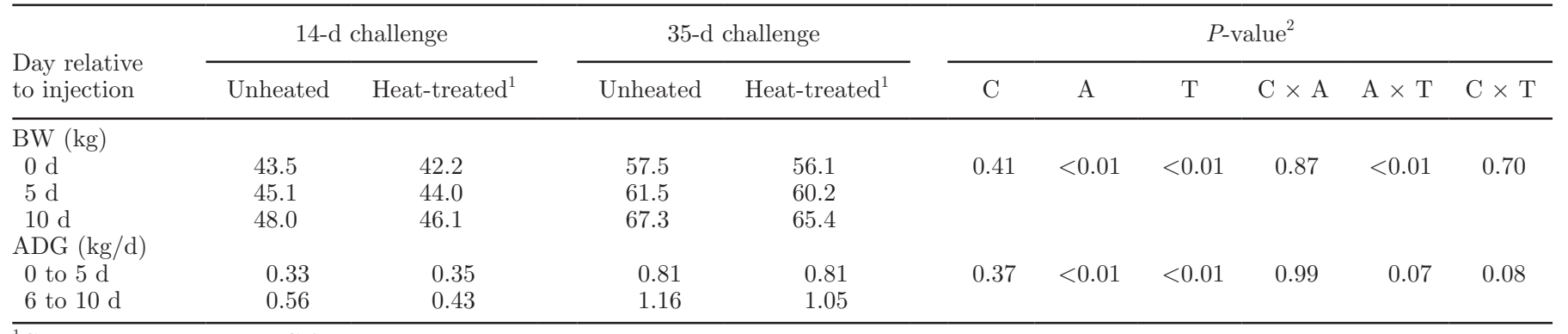

${ }^{1}$ Colostrum heated to $60^{\circ} \mathrm{C}$ for $60 \mathrm{~min}$.

${ }^{2} \mathrm{C}=$ colostrum treatment; $\mathrm{A}=$ calf age $(14$ or $35 \mathrm{~d}) ; \mathrm{T}=$ time relative to injection. 

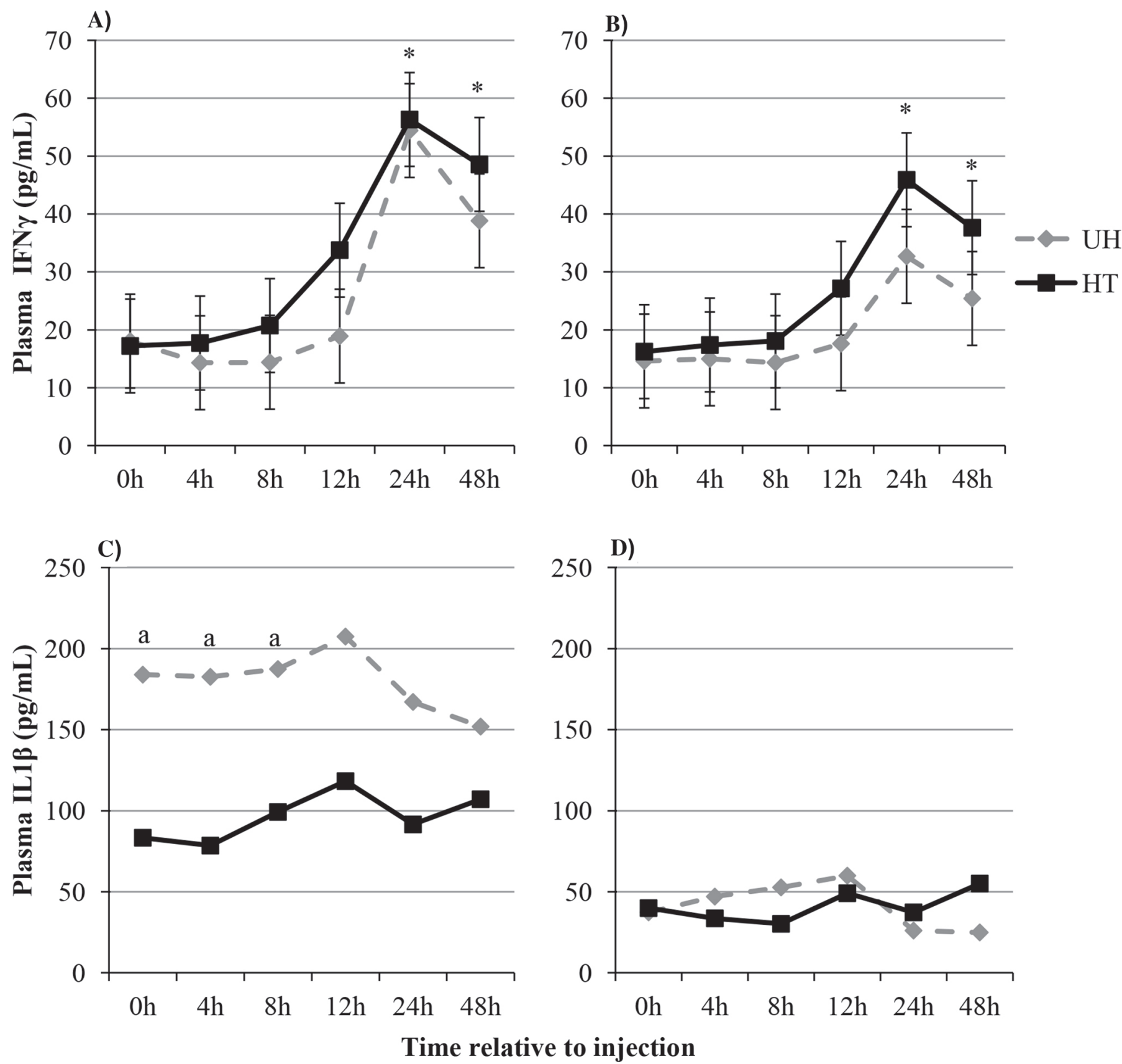

Figure 2. Plasma IFN $\gamma$ and IL1 $\beta$ concentrations after subcutaneous injection with $5.0 \mathrm{mg} / \mathrm{mL}$ ovalbumin at (A and C) $14 \mathrm{~d}$ and (B and D) $35 \mathrm{~d}$ of age in calves that received heat-treated $\left(60^{\circ} \mathrm{C}, 60 \mathrm{~min}\right.$; HT) or unheated (UH) colostrum at birth. Mean and SE values for IL1 $\beta$ analysis were back-transformed from log values used for analysis to correct skewness of residuals. Colostrum treatment did not affect plasma IFN $\gamma$ in calves at 14 or $35 \mathrm{~d}$ or IL13 at $35 \mathrm{~d}(P>0.05)$. Plasma IL13 was lower in HT calves at $14 \mathrm{~d}(P=0.03)$. Time after injection $(P<0.01)$ but not calf age $(P>0.05)$ affected plasma IFN $\gamma$ concentration. Plasma IL1 $\beta$ was lower in calves at $35 \mathrm{~d}(P<0.01)$ and changed with time after injection $(P<0.01)$. *Indicates concentration was different from that at time 0. Letter (a) indicates differences between treatments. Error bars represent standard errors of individual treatment means at each time point.

HT calves, likely due to very high initial concentration (Donahue et al., 2012).

The ability of colostrum heat treatment to reduce total bacteria, specifically coliform count, is an important contributor to the increased IgG absorption efficiency and final blood $\operatorname{IgG}$ concentrations often observed in calves fed heat-treated colostrum (Godden et al., 2012; Gelsinger et al., 2015a). Therefore, low total bacterial and coliform counts, combined with lower IgG ingestion, likely explain the inability of heat treatment to 
increase plasma IgG concentration for HT calves in the present study. Still, all HT calves achieved plasma concentrations well above the threshold necessary for successful passive transfer of immunity $(10 \mathrm{mg} / \mathrm{mL}$; Butler, 1969).

\section{IL1 $\beta$ and IFNY}

Goto et al. (1997) determined that calf serum concentrations of IL1 $\beta$ were positively correlated with IL1 $\beta$ concentration in ingested colostrum. Hagiwara et al. (2001) demonstrated that the same cytokine was absorbed by newborn calves and induced greater lymphocyte proliferation and neutrophilic oxidative burst when orally dosed; similar results were observed in calves fed whole colostrum. Further research demonstrated greater stimulation of neonatal lymphocytes following exposure to colostral cytokines, implying that cytokines provided in colostrum are important for neonatal immune development (Yamanaka et al., 2003).

Heating colostrum to $60^{\circ} \mathrm{C}$ for 60 min resulted in lower IL1 $\beta$ concentration in serum and plasma 24 to $48 \mathrm{~h}$ and $14 \mathrm{~d}$ after birth. Aggregation and precipitation of IL1 $\beta$ has been reported in aqueous solutions at temperatures $>39^{\circ} \mathrm{C}$ ( $\mathrm{Gu}$ et al., 1991). Colostrum heat treatment may have caused aggregation or precipitation of IL1 $\beta$, rendering it unavailable for absorption by the calf. Greater endogenous production may also explain higher serum IL1 $\beta$ concentration in UH calves. Quantifiable mRNA (Yamanaka et al., 2003) and complete cytokine protein production (Nonnecke et al., 2012) from neonatal calf leukocytes has been reported by others; it is possible that greater bacterial concentration in unheated colostrum provides larger stimulation of neonatal immune cells, resulting in higher plasma cytokine concentrations.

To our knowledge, this is the first study to explore the effect of colostrum heat treatment on cytokine absorption and immune response. For this reason, we chose only a few cytokines for analysis and did not include cell number and function. Although heat treatment reduced circulating IL1 $\beta$ without affecting other aspects of the immune response, more thorough investigations are necessary to confirm this conclusion.

\section{Growth}

Colostrum treatment did not affect overall growth rate $(P=0.37)$. However, the interactions of calf age and colostrum treatment with time post-injection indicate that the calves tended to show greater loss in ADG at $35 \mathrm{~d}$ than at $14 \mathrm{~d}(P=0.07)$, and ADG tended to be higher in UH than HT calves 6 to $10 \mathrm{~d}$ after the ovalbumin injection $(P=0.08)$. The 2 -way interaction of colostrum treatment and time post-injection implies that UH colostrum allows calves to recover their full potential for growth more quickly following an immune challenge than HT colostrum. Apparently, the rate of growth increased in HT calves during the days between immune challenge periods, because actual BW at 35 $\mathrm{d}$ was not different between groups. It is unclear why this response was delayed in HT compared with UH calves, but it may be related to factors other than the cytokines measured in the current study. Others have shown losses in colostrum IGF-1 and lactoferrin concentrations after heating at $60^{\circ}$ for $60 \mathrm{~min}$ (Abd El-Fattah et al., 2014). The effects of heat on other biologically active factors and possible ramifications for calf health and growth have yet to be described.

\section{Antibody Production}

As expected, we observed no evidence of antibody production following the initial ovalbumin injection at $14 \mathrm{~d}$ (Chase et al., 2008). We did observe defined B-cell activity following ovalbumin injection at $35 \mathrm{~d}$, with a clear increase in ovalbumin-specific IgG production $3 \mathrm{~d}$ post-injection (Figure 3). This time course of antigenspecific IgG production is in agreement with others, indicating measurable increases in IgG in response to ovalbumin challenge within 7 to $10 \mathrm{~d}$ post-injection (Lake et al., 2006; Ballou and DePeters, 2008). Therefore, heat treatment of colostrum had no effect on neonatal B-cell function.

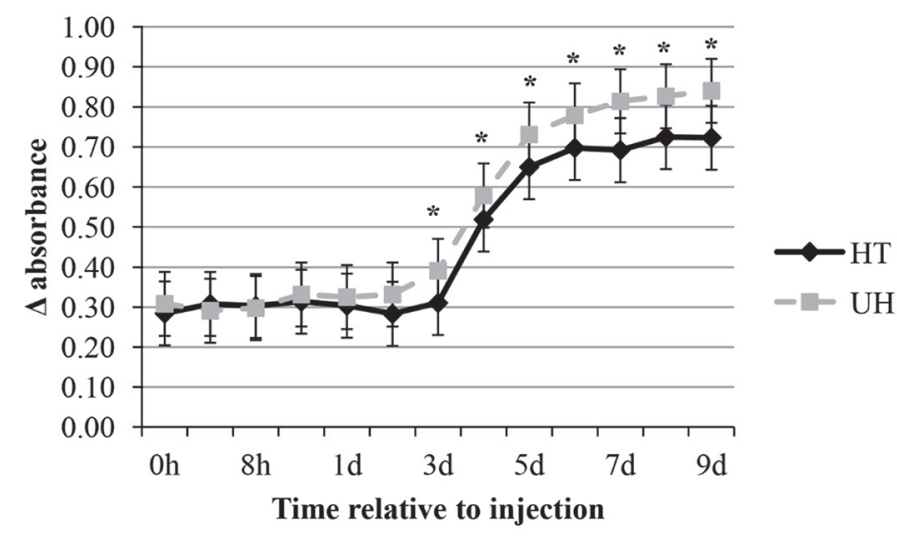

Figure 3. Change in ovalbumin-specific $\operatorname{IgG}$ concentration in sera after subcutaneous injection with $5.0 \mathrm{mg} / \mathrm{mL}$ ovalbumin at $35 \mathrm{~d}$ of age in calves that received heat-treated $\left(60^{\circ} \mathrm{C}, 60 \mathrm{~min}\right.$; HT) or unheated (UH) colostrum at birth. Ovalbumin-specific IgG concentration changed with time after injection $(P<0.01)$ but was not affected by colostrum treatment $(P>0.05)$. * Indicates concentration was different from that at time 0 . Error bars represent standard errors of individual treatment means at each time point. 


\section{CONCLUSIONS}

Feeding colostrum heated to $60^{\circ} \mathrm{C}$ for $60 \mathrm{~min}$ to newborn dairy calves reduced circulating IL1 $\beta$ through $14 \mathrm{~d}$ of age. Despite a lower IL1 $\beta$ concentration, we observed no differences in body temperature, IFN $\gamma$, or IgG; however, calves fed UH colostrum tended to regain ADG more rapidly following ovalbumin injection. These results indicate that HT colostrum does not inhibit the neonatal immune response but may affect recovery from exogenous antigen challenge. Further research is needed to continue characterizing the role of colostrum factors in neonatal development, including comparisons of immune cell function and activity, in addition to cytokines and growth factors that were not included in the present study.

\section{ACKNOWLEDGMENTS}

This paper is a component of USDA Regional Research Project NC-2042, Management Systems to Improve the Economic and Environmental Sustainability of Dairy Enterprises. The authors thank Evergreen Farms (Warriers Mark, PA) for supplying bull calves for this experiment; Mary Curran and Gaurav Deshmukh of Penn State University for technical support during cytokine analyses; and Linda Truong, Ashley Sutton, and Chad Heffner from Penn State University for assistance with animal care.

\section{REFERENCES}

Abd El-Fattah, A. M., F. H. R. Abd Rabo, S. M. El-Dieb, and H. A. Satar El-Kashef. 2014. Preservation methods of buffalo and bovine colostrum as a source of bioactive components. Int. Dairy J. 39:24-27.

AOAC International. 2000. Official Methods of Analysis. 17th ed. AOAC International, Gaithersburg, MD.

Ballou, M. A., and E. J. DePeters. 2008. Supplementing milk replacer with omega-3 fatty acids from fish oil on immunocompetence and health of Jersey calves. J. Dairy Sci. 91:3488-3500.

Benjamin, A. L., F. T. Korkmaz, T. H. Elsasser, and D. E. Kerr. 2016 Neonatal lipopolysaccharide exposure does not diminish the innate immune response to a subsequent lipopolysaccharide challenge in Holstein bull calves. J. Dairy Sci. 99:5750-5763.

Bielmann, V., J. Gillan, N. R. Perkins, A. L. Skidmore, S. Godden, and K. E. Leslie. 2010. An evaluation of Brix refractometry instruments for measurement of colostrum quality in dairy cattle. J. Dairy Sci. 93:3713-3721.

Butler, J. E. 1969. Bovine immunoglobulins: A review. J. Dairy Sci. 52:1895-1909.

Chase, C. C., D. J. Hurley, and A. J. Reber. 2008. Neonatal immune development in the calf and its impact on vaccine response. Vet. Clin. North Am. Food Anim. Pract. 24:87-104.

Dinarello, C. A. 2009. Immunological and inflammatory functions of the interleukin-1 family. Annu. Rev. Immunol. 27:519-550.

Donahue, M., S. M. Godden, R. Bey, S. Wells, J. M. Oakes, S. Sreevatsan, J. Stabel, and J. Fetrow. 2012. Heat treatment of colostrum on commercial dairy farms decreases colostrum microbial counts while maintaining colostrum immunoglobulin G concentrations. J. Dairy Sci. 95:2697-2702.
Elizondo-Salazar, J. A., and A. J. Heinrichs. 2009. Feeding heat-treated colostrum to neonatal dairy heifers: Effects on growth characteristics and blood parameters. J. Dairy Sci. 92:3265-3273.

Elizondo-Salazar, J. A., B. M. Jayarao, and A. J. Heinrichs. 2010. Effect of heat treatment of bovine colostrum on bacterial counts, viscosity, and Immunoglobulin G concentration. J. Dairy Sci. 93:961-967.

Gelsinger, S. L., C. M. Jones, and A. J. Heinrichs. 2015a. Effect of colostrum heat treatment and bacterial population on immunoglobulin $\mathrm{G}$ absorption and health of neonatal calves. J. Dairy Sci. 98:4640-4645.

Gelsinger, S. L., A. M. Smith, C. M. Jones, and A. J. Heinrichs. 2015b. Technical note: Comparison of radial immunodiffusion and ELISA for quantification of bovine immunoglobulin $\mathrm{G}$ in colostrum and plasma. J. Dairy Sci. 98:4084-4089.

Godden, S. 2008. Colostrum management for dairy calves. Vet. Clin. North Am. Food Anim. Pract. 24:19-39.

Godden, S., S. McMartin, J. Feirtag, J. Stabel, R. Bey, S. Goyal, L. Metzger, J. Fetrow, S. Wells, and H. Chester-Jones. 2006. Heattreatment of bovine colostrum. II: Effects of heating duration on pathogen viability and immunoglobulin. J. Dairy Sci. 89:34763483.

Godden, S. M., D. J. Smolenski, M. Donahue, J. M. Oakes, R. Bey, S. Wells, S. Sreevatsan, J. Stabel, and J. Fetrow. 2012. Heat-treated colostrum and reduced morbidity in preweaned dairy calves: results of a randomized trial and examination of mechanisms of effectiveness. J. Dairy Sci. 95:4029-4040.

Goto, M., M. Maruyama, K. Kitadate, R. Kirisawa, Y. Obata, M. Koiwa, and H. Iwai. 1997. Detection of interleukin-1 beta in sera and colostrum of dairy cattle and in sera of neonates. J. Vet. Med. Sci. 59:437-441.

Gu, L. C., E. A. Erdos, H. S. Chiang, T. Calderwood, K. Tsai, G. C. Visor, J. Duffy, W. C. Hsu, and L. C. Foster. 1991. Stability of interleukin 1 beta (IL-1 beta) in aqueous solution: Analytical methods, kinetics, products, and solution formulation implications. Pharm. Res. 8:485-490.

Hagiwara, K., S. Kataoka, H. Yamanaka, R. Kirisawa, and H. Iwai. 2000. Detection of cytokines in bovine colostrum. Vet. Immunol. Immunopathol. 76:183-190

Hagiwara, K., H. Yamanaka, H. Higuchi, H. Nagahata, R. Kirisawa, and H. Iwai. 2001. Oral administration of IL-1 beta enhanced the proliferation of lymphocytes and the $\mathrm{O}-2(-)$ production of neutrophil in newborn calf. Vet. Immunol. Immunopathol. 81:59-69.

Hall, M. B. 2009. Determination of starch, including maltooligosaccharides, in animal feeds: Comparison of methods and a method recommended for AOAC collaborative study. J. AOAC Int. 92:42-49.

Heinrichs, A. J., and B. S. Heinrichs. 2011. A prospective study of calf factors affecting first-lactation and lifetime milk production and age of cows when removed from the herd. J. Dairy Sci. 94:336-341.

Houser, B. A., S. C. Donaldson, S. I. Kehoe, A. J. Heinrichs, and B. M. Jayarao. 2008. A survey of bacteriological quality and the occurrence of salmonella in raw bovine colostrum. Foodborne Pathog. Dis. 5:853-858.

Johnson, J. L., S. M. Godden, T. Molitor, T. Ames, and D. Hagman. 2007. Effects of feeding heat-treated colostrum on passive transfer of immune and nutritional parameters in neonatal dairy calves. J. Dairy Sci. 90:5189-5198.

Kehoe, S. I., B. M. Jayarao, and A. J. Heinrichs. 2007. A survey of bovine colostrum composition and colostrum management practices on Pennsylvania dairy farms. J. Dairy Sci. 90:4108-4116.

Kryzer, A. A., S. M. Godden, and R. Schell. 2015. Heat-treated (in single aliquot or batch) colostrum outperforms non-heat-treated colostrum in terms of quality and transfer of immunoglobulin $\mathrm{G}$ in neonatal Jersey calves. J. Dairy Sci. 98:1870-1877.

Kushibiki, S., K. Hodate, H. Shingu, Y. Obara, E. Touno, M. Shinoda and Y. Yokomizo. 2003. Metabolic and lactational responses during recombinant bovine tumor necrosis factor-alpha treatment in lactating cows. J. Dairy Sci. 86:819-827.

Lake, S. L., E. J. Scholljegerdes, W. T. Small, E. L. Belden, S. I. Paisley, D. C. Rule, and B. W. Hess. 2006. Immune response and serum immunoglobulin $\mathrm{G}$ concentrations in beef calves suckling 
cows of differing body condition score at parturition and supplemented with high-linoleate or high-oleate safflower seeds. J. Anim. Sci. 84:997-1003.

Lesmeister, K. E., and A. J. Heinrichs. 2004. Effects of corn processing on growth characteristics, rumen development, and rumen parameters in neonatal dairy calves. J. Dairy Sci. 87:3439-3450.

Lochmiller, R. L., and C. Deerenberg. 2000. Trade-offs in evolutionary immunology: Just what is the cost of immunity? Oikos 88:87-98.

McMartin, S., S. Godden, L. Metzger, J. Feirtag, R. Bey, J. Stabel, S Goyal, J. Fetrow, S. Wells, and H. Chester-Jones. 2006. Heat treatment of bovine colostrum. I: Effects of temperature on viscosity and immunoglobulin G level. J. Dairy Sci. 89:2110-2118.

NAHMS. 2016. Dairy Cattle Management Practices in the United States, 2014. USDA, Fort Collins, CO.

Nguyen, T. V., L. Yuan, M. S. Azevedo, K. I. Jeong, A. M. Gonzalez, and L. J. Saif. 2007. Transfer of maternal cytokines to suckling piglets: In vivo and in vitro models with implications for immunomodulation of neonatal immunity. Vet. Immunol. Immunopathol. $117: 236-248$

Nonnecke, B. J., W. R. Waters, M. R. Foote, M. V. Palmer, B. L. Miller, T. E. Johnson, H. B. Perry, and M. A. Fowler. 2005. Development of an adult-like cell-mediated immune response in calves after early vaccination with Mycobacterium bovis bacillus Calmette-Guerin. J. Dairy Sci. 88:195-210.

Nonnecke, B. J., W. R. Waters, J. P. Goff, and M. R. Foote. 2012. Adaptive immunity in the colostrum-deprived calf: Response to early vaccination with Mycobacterium bovis strain bacille Calmette Guerin and ovalbumin. J. Dairy Sci. 95:221-239.
Oliver, J. C., L. A. Bland, C. W. Oettinger, M. J. Arduino, S. K. McAllister, S. M. Aguero, and M. S. Favero. 1993. Cytokine kinetics in an in vitro whole-blood model following an endotoxin challenge. Lyphokine Cytokine Res. 12:115-120.

Pritchett, L. C., C. C. Gay, D. D. Hancock, and T. E. Besser. 1994. Evaluation of the hydrometer for testing immunoglobulin G1 concentrations in Holstein colostrum. J. Dairy Sci. 77:1761-1767.

Quigley, J. D., and J. J. Drewry. 1998. Nutrient and immunity transfer from cow to calf pre- and postcalving. J. Dairy Sci. 81:2779-2790.

Stott, G. H., D. B. Marx, B. E. Menefee, and G. T. Nightengale. 1979. Colostral immunoglobulin transfer in calves. 1. Period of absorption. J. Dairy Sci. 62:1632-1638.

Tyler, J. W., D. D. Hancock, S. M. Parish, D. E. Rea, and T. E. Besser. 1996. Evaluation of 3 assays for failure of passive transfer in calves. J. Vet. Intern. Med. 10:304-307.

Windeyer, M. C., K. E. Leslie, S. M. Godden, D. C. Hodgins, K. D. Lissemore, and S. J. LeBlanc. 2012. The effects of viral vaccination of dairy heifer calves on the incidence of respiratory disease, mortality, and growth. J. Dairy Sci. 95:6731-6739.

Yamanaka, H., K. Hagiwara, R. Kirisawa, and H. Iwai. 2003. Proinflammatory cytokines in bovine colostrum potentiate the mitogenic response of peripheral blood mononuclear cells from newborn calves through IL-2 and CD25 expression. Microbiol. Immunol. 47:461-468.

Yang, M., Y. Zou, Z. H. Wu, S. L. Li, and Z. J. Cao. 2015. Colostrum quality affects immune system establishment and intestinal development of neonatal calves. J. Dairy Sci. 98:7153-7163. 